\title{
Study of ST Stock Market Volatility with Nonlinear Method
}

\author{
Wu Yu-dong \\ School of Basic Science, Harbin University of Commerce
}

\begin{abstract}
As a kind of stock treated specially, ST stock has higher risks as well as high revenues; so, it is of great significance to study the market volatility of ST stocks in Chinese stock market. The 745 index return rates of ST stocks from April 1st, 2010 to April 26th, 2013are studied with nonlinear method. It is demonstrated: ST index return rate has peak fat-tail characteristics and heteroskedasticity; the EGARCH model established on the sequences of ST index return rate shows that there is obvious leverage effect in Chinese stock market. Meanwhile, it could also be known from the study that GARCH model fits best the return rate sequence, through which short-term prediction of ST index is conducted, predicting correctly the short-term several-day movements with stable results.
\end{abstract}

Keywords: ARCH model; ST stocks; volatility; leverage effect

\section{Introduction}

Prices of stock market contain abundant information, involving mainly various aspects of the operation of stock market; however, the prices of stocks are fluctuating all the time. Studies have found that clustering often occurs to some financial time series and the variance will varies with the time, such phenomenon is against the hypothesis that the random error term of the model complies with the same variant, meanwhile, it will also lead to peak fat-tail of the distribution of the stock prices in stock market. The influencing factors of the fluctuation of stock prices are diversified and complex, so the return rate of stock price is a good index for studying stocks. Establish $\mathrm{ARCH}$ model, GARCH model and other expanding models for the return rate of stock prices and make empirical analysis; excavate important economic information contained in the results of the empirical analysis so as to offer decision support to funds managers, investors and governmental regulators. All these models have gained extensive application in fluctuation of return rate, market risk assessment and fluctuation in prices with better results $^{[1]}$.

\section{Overview of ARCH family model}

\section{(I) ARCH model}

There are various ways to define Conditional Heteroskedasticity (ARCH). At present what is used often is the definition put forward in 1982 by Engle. If there is a random process $\left\{\varepsilon_{t}\right\}, \varepsilon_{t}^{2}$ will comply with the process of $\operatorname{AR}(q)$ :

$$
\varepsilon_{t}^{2}=\alpha_{0}+\alpha_{1} \varepsilon_{t-1}^{2}+\ldots+\alpha_{q} \varepsilon_{t-q}{ }^{2}+\eta_{t}
$$

Among which, $\left\{\eta_{t}\right\}$ is independent identically distributed, and,

$$
E\left(\eta_{t}\right)=0, D\left(\eta_{t}\right)=\lambda^{2}, t=1,2, \ldots, T,
$$

then it could be said that $\left\{\varepsilon_{t}\right\}$ complies with the ARCH process of $q$ stage, which could be marked as $\varepsilon_{t} \sim \operatorname{ARCH}(q)$. For convenience of 
studying, $A R C H(q)$ model is usually expressed as

$\varepsilon_{t}=h_{t} v_{t}$, among which $\left\{v_{t}\right\}$ is independent identically distributed, and, $E\left(v_{t}\right)=0, D\left(v_{t}\right)=1$ could be expressed as

$$
h_{t}^{2}=\alpha_{0}+\alpha_{1} \varepsilon_{t-1}^{2}+\ldots+\alpha_{q} \varepsilon_{t-q}^{2}
$$

(II) GARCH model

If sequence $\varepsilon_{t}$ could be expressed as:

$$
\begin{aligned}
\varepsilon_{t} & =h_{t} v_{t}, \\
h_{t}^{2}= & \alpha_{0}+\alpha_{1} \varepsilon_{t-1}{ }^{2}+\ldots+\alpha_{q} \varepsilon_{t-q}{ }^{2} \\
& +\beta_{1} h_{t-1}^{2}+\ldots+\beta_{p} h_{t-p}{ }^{2}
\end{aligned}
$$

Among which, $\left\{v_{t}\right\}$ is independent identically distributed, and, $v_{t} \sim N(0,1), t=1,2, \ldots, T$. The process $\varepsilon_{t}=h_{t} v_{t}$ thus derived from the above definition is known as generalized ARCH process, which could be marked as $\varepsilon_{t} \sim G A R C H(p, q)$.

There are generally three hypotheses about the error distribution of GARCH model:

1) Error $\varepsilon_{t}$ is normally distributed:

$$
\varepsilon_{t} \sim N(0,1)
$$

2) Distribution of $\varepsilon_{t}: \varepsilon_{t} \sim t(\lambda)$, among which $t(\lambda)$ is the mean value 0 and the degrees freedom is $t$ distribution of $\lambda$;

3) Error $\varepsilon_{t}$ is GED distributed: whose probability density function is

$$
\begin{aligned}
& f(x)=\frac{1}{2 \sigma_{p} p^{\frac{1}{p}} \Gamma\left(1+\frac{1}{p}\right)} \exp \left(-\frac{|x-\mu|^{p}}{p \sigma_{p}^{p}}\right) \\
& -\infty<x<+\infty,-\infty<\mu<+\infty, \sigma_{p}>0, p>0
\end{aligned}
$$

In ARCH process of $\varepsilon_{t}=\sqrt{h_{t}} v_{t}$, $\left\{v_{t}\right\}$ is independent identically distributed, and, $E\left(v_{t}\right)=0, D\left(v_{t}\right)=1$. If it is supposed that the conditional variance $h_{t}$ has the following formula

$$
\begin{aligned}
\ln h_{t}= & \alpha_{0}+\sum_{i=1}^{p} \alpha_{i}\left|\frac{\varepsilon_{t-i}}{\sqrt{h_{t-i}}}-E\left(\frac{\varepsilon_{t-i}}{\sqrt{h_{t-i}}}\right)\right| \\
& +\sum_{k=1}^{r} \lambda_{k} \frac{\varepsilon_{t-k}}{\sqrt{h_{t-k}}}+\sum_{j=1}^{q} \beta_{j} \ln h_{t-1}
\end{aligned}
$$

Then it could be said that $\left\{\varepsilon_{t}\right\}$ complies with EGARCH process of $q$ stage. The conditional variance $h_{t}$ of EGARCH model is expressed with exponential form. $h_{t}$ is nonnegative and the leverage effect is of exponential type. $\lambda_{k} \neq 0$ shows that the informational function is asymmetric.

\section{Establishment and analysis of non- linear model of ST index return rate}

\subsection{Data analysis}

This essay analyzed the rules of the stock price index volatility in Shanghai Stock Market of China. The index of Shenzhen ST plate (composed of 27 ST stocks) was selected, ranging from January $4^{\text {th }}, 2011$ to April $26^{\text {th }}, 2013$, altogether 745 closing prices as samples. (Data resources from Great Wisdom) Suppose $s_{t}$ is the closing price of ST index on $t$ trading day, $p_{t}$ is daily return rate: $p_{t}=\ln \left(s_{t}\right)-\ln \left(s_{t-1}\right)$. Time sequence chart of the return rate and the statistical characteristic of the sequence see Fig.1.

(III) EGARCH model 


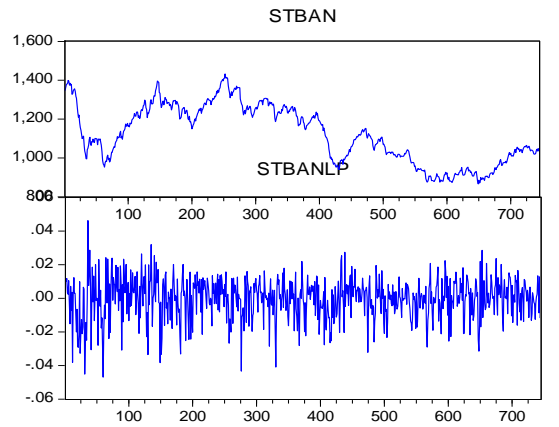

Fig. 1 Wave Pattern of ST index return rate

From Fig.1 it could be seen that the fluctuation of return rate of compositional index of Shenzhen Stock Market has the phenomenon of "clustering", therefore, it could judged that the sequence might have ARCH effects. To know better the nature of the sequence of return rate, we conducted statistical test and unit root test to the sequence ${ }^{[2]}$.

The analysis results show that the return rate sequence of ST index is of the state of peak fat-tail and the sequence has no unit root and the sequence is steady.

The autocorrelation and partial autocorrelation tables and Q statistics of ST stock return rate sequences are obtained with Eviews to test the correlations of return rate sequences. The autocorrelation and partial autocorrelation are shown in Table 2, from which it could be seen that return rate sequences not only have sequence correlation, but each item is not independent, so it is considered that heteroskedasticity might exist in the return rate sequences.

\begin{tabular}{|c|c|c|c|c|c|c|}
\hline Autocorrelation & Partial Correlation & & $A C$ & PAC & Q-Stat & Prob \\
\hline صا & صا & 1 & 0.178 & 0.178 & 23.576 & 0.000 \\
\hline 10 & $\sqrt{11}$ & 2 & 0.066 & 0.035 & 26.786 & 0.000 \\
\hline 中 & 1] & 3 & 0.083 & 0.068 & 31.947 & 0.000 \\
\hline II & d & 4 & -0.027 & -0.057 & 32.491 & 0.000 \\
\hline . 1 & 1. 1 & 5 & -0.033 & -0.026 & 33.290 & 0.000 \\
\hline त 1 & $\sqrt{1}$ & 6 & -0.035 & -0.029 & 34.225 & 0.000 \\
\hline ימו & ip & 7 & 0.036 & 0.058 & 35.203 & 0.000 \\
\hline 中 & 小 & 8 & 0.011 & 0.001 & 35.297 & 0.000 \\
\hline 10 & 中 & 9 & 0.065 & 0.064 & 38.450 & 0.000 \\
\hline 10 & ipr & 10 & 0.064 & 0.032 & 41.563 & 0.000 \\
\hline 中 & 川 & 11 & 0.013 & -0.008 & $41.688^{\circ}$ & 0.000 \\
\hline 中 & 小 1 & 12 & 0.009 & -0.005 & 41.748 & 0.000 \\
\hline ipr & קי & 13 & 0.029 & 0.030 & 42.381 & 0.000 \\
\hline
\end{tabular}

Fig. 2 Correlation functions of ST index return rate sequences
We established autoregression moving average model for return rate sequences and established ARMA (2, 3) model based on the autocorrelation and partial correlation of ST index return rate sequences $^{[3]}$. The residual error sequences of ARMA $(2,3)$ were conducted heteroskedasticity test with ARCH-LM test method, the result of which sees Table 1.

Table 1 ARCH-LM test

\begin{tabular}{|l|llll|}
\hline \multirow{2}{*}{$\begin{array}{l}\text { ST index } \\
\text { return } \\
\text { rate }\end{array}$} & $\begin{array}{l}\text { F-statistic } \\
0.000\end{array}$ & 6.277341 & Prob (5,731) \\
\cline { 2 - 5 } & Obs*R-squared & 30.3416 & Prob (5) & 0 \\
\hline
\end{tabular}

From Table1 it could be seen that the corresponding probabilities of $F$ statistics and $R^{2}$ statistics are on the verge of 0 and the rejected residual error sequences have no ARCH effect null hypothesis, which shows that all the ST index return rate sequences have $\mathrm{ARCH}$ effect. It is necessary to establish ARCH family models to explain the hidden information in the wave phenomenon of return rate heteroscedasticity.

\subsection{Establishing ARCH model of ST index return rate}

To eliminate the heteroscedasticity of ST index return rate, we introduced ARCH model on the base of ARMA model. Through analysis, ARCH model at stage 5 could eliminate the ARCH effect of return rate sequences, where the ARCH model fits better. Therefore, we select ARCH (5) model for ST index return rate sequences. The estimated result of ARMA $(2,3)$-ARCH (5) model is obtained after the above analysis and repeated test:

$$
\begin{aligned}
& r_{t}=-0.3674 r_{t-1}+0.5032 r_{t-2}+\varepsilon_{t} \\
& +0.5293 \varepsilon_{t-1}-0.3961 \varepsilon_{t-2}+0.014 \varepsilon_{t-3} \\
& \sigma_{t}^{2}=0.000112+0.0393 \sigma_{t-1}^{2}+0.0298 \sigma_{t-2}^{2} \\
& +0.0364 \sigma_{t-3}^{2}+0.0109 \sigma_{t-4}^{2}+0.1071 \sigma_{t-5}^{2}
\end{aligned}
$$


Test whether ST index return rate sequences still have ARCH effect, the result of which is shown in Table 4. It could be seen that the accompanying probability is large, i.e. the probability of rejecting null hypothesis errors is large. So, we accept the null hypothesis and the ST index return rate sequences has no $\mathrm{ARCH}$ effect after the establishment of ARCH (5) model; however, the stage of the established ARCH model is higher. So, fitting could be conducted by establishing GARCH model of low stages.

\subsection{Establishment of GARCH models under different distributions of ST in- dex}

We established ARMA $(2,3)-G A R C H$ $(1,1)$ model of ST index return rate sequences.

The model equation structure is:

$$
\begin{gathered}
r_{t}=-0.5569 r_{t-1}+0.3136 r_{t-2}+\varepsilon_{t} \\
+0.7266 \varepsilon_{t-1}-0.1796 \varepsilon_{t-2}+0.0283 \varepsilon_{t-3} \\
\sigma_{t}^{2}=3.3 \times 10^{-6}+0.03943 \varepsilon_{t-1}^{2}+0.9374 \sigma_{t-1}^{2}
\end{gathered}
$$

The sum of the coefficients of ARCH and GARCH in the model is 0.9768, which is in accordance with the hypothesis of GARCH model, close to 1, i.e. the shock effect of the return would last for a long time before it declines gradually, which shows that the wave has strong continuity $^{[4]}$.

GARCH $(1,1)$ model of ST index return rate. Since the larger the Log likelihood is, the better the fitting effect of the model is; the smaller the AIC and the $\mathrm{BIC}$ value is, the proper the lagging stage selection of the explaining variables of the model is, which shows the GARCH (1.1) model has better fitting effects.

Different error distribution is of great significance for the fitting effect of the models. In the following, ST index return rate is analyzed in terms of $\operatorname{ARMA}(2,3)$ GARCH $(1,1)$ model established on different distributions of the errors of
GARCH models. The model is as the follows:

(1) $\varepsilon_{t}$ is normally distributed:

$r_{t}=-0.743 r_{t-1}-0.1256 r_{t-2}+\varepsilon_{t}$ $+0.9177 \varepsilon_{t-1}+0.0439 \varepsilon_{t-2}+0.0565 \varepsilon_{t-2}$ $\sigma_{t}^{2}=2.60 \times 10^{-6}+0.03275 \varepsilon_{t-1}^{2}+0.9484 \sigma_{t-1}^{2}$

(2) $\varepsilon_{t}$ is t distributed:

$r_{t}=-0.5812 r_{t-1}+0.3032 r_{t-2}+\varepsilon_{t}$ $+0.7458 \varepsilon_{t-1}-0.1648 \varepsilon_{t-2}+0.0302 \varepsilon_{t-2}$ $\sigma_{t}^{2}=3.35 \times 10^{-6}+0.0417 \varepsilon_{t-1}^{2}+0.9352 \sigma_{t-1}^{2}$

(3) $\varepsilon_{t}$ is GED distributed:

$r_{t}=-0.05563 r_{t-1}+0.3142 r_{t-2}+\varepsilon_{t}$ $+0.7260 \varepsilon_{t-1}-0.1804 \varepsilon_{t-2}+0.0282 \varepsilon_{t-2}$ $\sigma_{t}^{2}=3.30 \times 10^{-6}+0.0394 \varepsilon_{t-1}^{2}+0.9374 \sigma_{t-1}^{2}$

Through establishing GARCH model of ST index under different error distributions, it could be concluded that in different error distributions of ARMA-GARCH, the model whose error is based on GED distribution fits the best after analyzing comprehensively the evaluation indexes. Next to it is t distribution and normal distribution.

\subsection{Establishing EGARCH model of ST index}

Though GARCH model could explain well the clustering of the wave of return rate sequences, it could not explain the "leverage effect" existing in time return rate sequences, i.e. whether the bad news of the stock market (drop of the return rate) would produce bigger shock than the good news with the equal degrees (rise of the return rate). Therefore, EGARCH model of the ARCH model family is used to test the "leverage effect" of the return rate sequences and to explain the fluctuation of the impact of the information on ST stocks. Establish EARCH model for ST index return rate.

The model equation is as the follow: 
$R_{t}=-0.3645 R_{t-1}+0.5073 R_{t-2}+\varepsilon_{t}$

$+0.5304 \varepsilon_{t-1}-0.4031 \varepsilon_{t-2}+0.0059 \varepsilon_{t-3}$

$\ln \left(\sigma_{t}^{2}\right)=-0.6136+0.0809\left|\frac{\varepsilon_{t-1}}{\sigma_{t-1}}\right|$

$-0.0702 \frac{\varepsilon_{t-1}}{\sigma_{t-1}}+0.9380 \ln \left(\sigma_{t-1}^{2}\right)$

The logarithm likelihood value of the fitting results of the EGARCH (1.1) of ST index increases compared with that of the ARCH model fitting while both AIC value and BIC values drop, which shows that EGARCH (1.1) model has better fitting results than ARCH model. It is concluded through analysis that the leverage effect coefficient of EGARCH model of $\mathrm{ST}$ index return rate $\varphi=c(8)=-0.0702$.

So, it could be known that there is leverage effect in ST stock market ${ }^{[5]}$. The information impact on ST index return rate could be expressed that when $\varepsilon_{t-1}>0$ (i.e. ST plate market is shocked by good news), the information has a 0.0107 times (|0.0809-0.0702 $)$ impact on ST index return rate and when $\varepsilon_{t-1}<0$ (i.e. ST plate market is shocked by bad news), this information will have a 0.1511 times $(\mid 0.0809+0.0702) \mid)$ impact on ST index return rate. Thus, bad new of equal amount has larger shocks on ST index stock market return rate than good news.

\section{Short-term prediction and evalua- tion of ST index}

Since GARCH $(1,1)$ model could better imitate the volatility of ST index return rate, we choose it to make short-term prediction and error of mean square is used to evaluate the model prediction.

741 samples were selected in this study to establish GARCH model, reserving 4 observed value and predicted value for comparison to observe the predictive ability of the model. GARCH (1.1) model is used to predict the ST index on April 23,
2013, the result of which is shown in Table 2 .

Table 2 Comparison of the actual value and the predicted value

\begin{tabular}{|c|c|c|c|}
\hline Date & $\begin{array}{c}\text { Pre- } \\
\text { dicted } \\
\text { value }\end{array}$ & $\begin{array}{c}\text { Actual } \\
\text { value }\end{array}$ & $\begin{array}{c}\text { Error of mean } \\
\text { square }\end{array}$ \\
\hline April 23, 2013 & 1035.58 & 1045.02 & 0.009468 \\
\hline April 24, 2013 & 1034.88 & 1035.24 & 0.007491 \\
\hline April 25, 2013 & 1035.48 & 1048.97 & 0.000015 \\
\hline April 26, 2013 & 1034.93 & 1036.74 & 0.00000716 \\
\hline
\end{tabular}

From Table 4 it could be known that there are differences between the predicted value and the actual value. However considering from the aspect of error of mean square, the prediction is steady, which shows that GARCH (1.1) model have better fitting effects, which could predict the tendencies of four days and the prediction has certain stability. With Chinese supervision system becomes stringent and the force of striking violations of laws, it is justified to believe that GARCH model would be more correct in predicting ST index.

\section{Acknowledgment}

This research was financially supported by the Department of Education of Heilongjiang Province under Grant No.12532083 and youth foundation of Harbin University of Commerce under Grant No.HCUL2013012.

\section{References}

[1] Xu Di-long, Zhang Yu. Empirical Research on the Relationship between CAPM and Shanghai Stock Market [J], Journal of Nanchang University (Natural Science), 2005, (4).

[2] Chikashi and Tsuji. Exploring the Priced Factors in ICAPM in Japan [J]. Modern Economy. 2011,2:701 705

[3] G.Q. Fu, W.Z. Liu. Study on Risk Analysis and Risk Measurement of ST Stock Price Volatility. Master 
Dissertation of Southwestern University, 2010.

[4] Zhang Rui-xin. Empirical Research of China's Stock Market Herd Behavior Based on CAPM [J], The Guide of

Science and Education, 2010, (35).
[5] Chen Mei. Based on the CAPM of Shanghai Stock Market Risk $\beta$ Coefficient Analysis[J],Guide To Business,2012,(5) 